\title{
Personalidade da Marca de Destinos e sua Relação com o Critério de Escolha dos Turistas Brasileiros
}

\section{Resumo}

Leonilde da Conceição Silva Lindemberg Costa Júnior

Este estudo teve como objetivo identificar o critério de escolha de turistas brasileiros ao decidirem por um destino para passarem suas férias. Utilizou-se modelo capaz de mensurar a personalidade da marca de destinos turísticos. Adotou-se metodologia quantitativa, com caráter descritivo e corte transversal. Os dados foram coletados por meio do formulário eletrônico TypeForm. Obteve-se um total de 268 respostas de turistas brasileiros. Em relação ao critério de escolha de um destino turístico os dados confirmam a hipótese principal que em média os turistas brasileiros se consideram muito criteriosos ao escolher por um destino turístico. Evidencia-se que o brasileiro planeja previamente suas viagens, e que o mesmo ao buscar informações sobre destinos leva em consideração as experiências de amigos e conhecidos, bem como realiza pesquisas na internet. Essas fontes de informações são relevantes para a decisão do turista brasileiro. Sugere-se que o turista brasileiro procura por destinos hospitaleiros e que possuam atividades destinadas tanto para adultos como para as crianças. Não obstante, o destino turístico deve ser ousado e emocionante, proporcionando boas recordações para os envolvidos na viagem.

Palavras-chave: Marketing Turístico; Personalidade da marca; Consumidor de turismo.

\section{Abstract \\ Personality of the Destination Brand and a Relation to the Brazilian Tourists 'selection Criteria}

This study aimed to identify the criteria for choosing Brazilian tourists when deciding on a destination to spend their holidays. A model capable of measuring the personality of the brand of tourist destinations was used. It was adopted a quantitative methodology, with descriptive character and cross section. Data were collected using the TypeForm electronic form. A total of 268 responses from Brazilian tourists were obtained. Regarding the criterion of choosing a tourist destination, the data confirm the main hypothesis that on average Brazilian tourists consider themselves very judicious when choosing a tourist destination. It is evident that Brazilians plan their travels in advance, and that when seeking information about destinations takes into account the experiences of friends and acquaintances, as well as conducts research on the Internet. These sources of information are relevant to the decision of the Brazilian tourist. It is suggested that Brazilian tourists look for hospitable destinations, and have activities designed for both adults and children. Nevertheless, the tourist destination must be bold and exciting, providing good memories for those involved in the trip.

Keywords: Tourism Marketing; Brand personality; Tourism consumer.

a. Mestrado em Contabilidade e Administração pela Fundação Instituto Capixaba de Pesquisas em Contabilidade, Economia e Finanças, São Luís, MA, Brasil. E-mail: leonilde.mally@gmail.com.

b. Mestrado em Administração pela Fundação Instituto Capixaba de Pesquisas em Contabilidade, Economia e Finanças, Vitória, ES, Brasil. E-mail: lindemberg.junior@ifma.edu.br. 


\section{Resumen}

Personalidad de la Marca de Destino y Relación con los Criterios de Selección Turística Brasileña

Este estudio tuvo como objetivo identificar los criterios para elegir a los turistas brasileños al decidir un destino para pasar sus vacaciones. Se utilizó un modelo capaz de medir la personalidad de la marca de destinos turísticos. Se adoptó una metodología cuantitativa, con carácter descriptivo y sección transversal. Los datos fueron recolectados usando el formulario electrónico TypeForm. Se obtuvieron un total de 268 respuestas de turistas brasileños. Con respecto al criterio de elegir un destino turístico, los datos confirman la hipótesis principal de que, en promedio, los turistas brasileños se consideran muy juiciosos al elegir un destino turístico. Es evidente que los brasileños planean sus viajes con anticipación, y que cuando buscan información sobre los destinos se tienen en cuenta las experiencias de amigos y conocidos, y se realizan investigaciones en Internet. Estas fuentes de información son relevantes para la decisión del turista brasileño. Se sugiere que los turistas brasileños busquen destinos hospitalarios y tengan actividades diseñadas tanto para adultos como para niños. Sin embargo, el destino turístico debe ser audaz y emocionante, proporcionando buenos recuerdos para aquellos involucrados en el viaje.

Palabras clave: Comercialización de turismo; Personalidad de marca; Consumidor de turismo.

\section{INTRODUÇÃo}

As empresas de turismo em todo o mundo têm sido afetadas pela globalização e avanço constante das tecnologias, o que provocou um aumento da concorrência entre as mesmas, apresentando possibilidades e riscos (Hosany, Ekinci, \& Uysal, 2006; Buhalis \& Law, 2008). Diante deste cenário, os dirigentes das organizações de turismo sentiram a necessidade de desenvolver novas estratégias que lhes garantissem vantagem competitiva e permanência no mercado (Ekinci \& Hosany, 2006; Pimentel, Pinho, \& Vieira, 2006; Gómez-Aguilar, Guillén, \& Roman, 2016).

Nesse sentido, uma das estratégias adotadas pelos comerciantes de turismo tem sido a utilização de ferramentas de branding semelhantes às aplicadas no comércio de produtos (Usakli \& Baloglu, 2011). Para Qu, Kim e Im (2011) não é suficiente que um destino turístico esteja entre os destinos potenciais do mercado, uma vez que há uma grande quantidade de destinos com traços parecidos concorrendo com ele. Os autores afirmam que é preciso que os destinos desenvolvam uma personalidade da marca capaz de possibilitar o seu reconhecimento e diferenciação pelo seu público alvo.

Desse modo, identificou-se na revisão da literatura estudos que investigam a personalidade da marca de destinos em diferentes contextos, por exemplo: Chen e Pou (2013); Ekinci e Hosany (2006); Guido e Peluso (2015); Hosany, Ekinci e Uysal (2007); Hultman et al.(2015); Kumar (2016); Li e Kaplanidou (2013); Murphy, Benckendorff e Moscardo (2007); Papadimitriou, Apostolopoulou e Kaplanidou (2015); Sahin e Baloglu (2011); Shin et al. (2017); Skarmeas, Oghazi e Beheshti (2015); Usakli e Baloglu (2011). No entanto, nota-se que estes estudos não identificam o critério de escolha de turistas ao decidirem por um destino para passar as suas férias, nem verificam a relação do critério de escolha dos mesmos com a personalidade da marca dos destinos turísticos.

Portanto, na intenção de avançar as investigações sobre a personalidade da marca de destinos, o presente estudo se propõe a preencher as lacunas 
apresentadas respondendo aos seguintes questionamentos: Qual é o critério de escolha dos turistas brasileiros em relação a um destino para passar as suas férias? Qual a associação do critério de escolha dos turistas brasileiros com a personalidade da marca de destinos turísticos?

Desse modo, o objetivo principal deste estudo é identificar o critério de escolha de turistas brasileiros ao decidir por um destino para passarem suas férias. Em particular, a presente pesquisa possui três objetivos específicos: perceber a relação entre o critério de escolha dos turistas e a personalidade da marca de destinos; verificar os traços que constituem a personalidade da marca de destinos na visão de turistas brasileiros e; identificar o grau de relevância de diferentes fontes de informações utilizadas por turistas brasileiros na busca por um destino turístico.

A presente investigação justifica-se teoricamente por abordar duas lacunas existentes na literatura. Uma é a identificação do critério de escolha dos turistasao decidir por um destino para passar as suas férias. A outra é a relação do critério de escolha dos turistas com a personalidade da marca de destinos turísticos. Este estudo se mostra relevante, visto que as pesquisas realizadas nesta área em sua maioria analisam os traços que formam a imagem e a personalidade da marca de destinos (Ekinci \& Hosany, 2006; Hosany, Ekinci, \& Uysal, 2007; Qu et al., 2011; Chen \& Pou, 2013; Kumar \& Nayak, 2014; Skarmeas, Oghazi, \& Beheshti, 2015), sendo necessário avançar os estudos sobre os efeitos da personalidade da marca dos destinos no comportamento dos turistas (Hultman, Skarmeas, Oghazi, \& Beheshti, 2015; Sharifsamet, Jin, \& Martin, 2020).

Como justificativa prática, a presente pesquisa torna-se relevante na perspectiva de que os gestores envolvidos neste setor poderão utilizar as informações disponibilizadas para criarem personalidades favoráveis da marca de seus destinos. Suprindo assim as expectativas dos seus clientes e favorecendo o marketing "boca a boca", o que consequentemente atrairá novos turistas e concederá vantagens competitivas (Llodrà-Riera, Martínez-Ruiz, Jimenez-Zarco, Izquierdo-Yusta, \& Santana, 2015; Tomazzoni, Possamai, \& Lovatel, 2010).

Para alcançar os objetivos deste estudo, realizou-se levantamento da literatura acerca do marketing turístico, marca de destinos, personalidade da marca de destinos turísticos e fontes de informações sobre destinos. Em seguida, adaptou-se as escalas de Aaker (1997), Hosany; Ekinci; Uysal (2006), Ekinci, Sirakaya-Turk e Baloglu (2007), Llodrà-Riera et al.(2015) e Kumar (2016) como ferramenta para coletar os dados. Utilizando-se de pesquisa quantitativa com caráter descritivo e corte transversal, realizou-se estatística descritiva e regressão linear para analisar os dados. E por fim, no último capítulo realizou-se as considerações finais sobre a pesquisa.

\section{REFERENCIAL TEÓRICO}

\section{Marketing Turístico}

O turismo é um fenômeno que move pessoas no mundo todo, o que o torna uma das principais fontes da economia em nível global (Sousa \& Simões, 2010). A expansão crescente do turismo, os aumentos da concorrência entre os destinos 
turísticos e as mudanças no comportamento dos turistas são grandes desafios para o marketing de turismo, pois dificultam ainda mais a tomada de decisão dos turistas na escolha por um destino (Kumar \& Nayak, 2014; Gómez-Aguilar et al., 2016). Neste cenário, o marketing tornou-se importante na formulação de estratégias para atrair e satisfazer viajantes (Beerli \& Martin, 2004).

Diante disso, o marketing turístico não deve apenas buscar atrair turistas, mas representar o gerenciamento de estratégias capazes de facilitar o desenvolvimento dos objetivos locais para o fornecimento do turismo, garantindo que as estratégias do destino obtenham êxito (Mazzon \& Vera, 2008). Assim, a sua função neste setor é vista como fortalecedora das relações com os turistas (Ahmed, 1991).

Desse modo, as pesquisas realizadas na área de marketing turístico se concentram nos traços que formam as imagens de destino (Hankinson, 2005). Entre esses estudos encontra-se o de Bramwell e Rawding (1996), que analisaram os motivos que levam os destinos a criarem imagens diferenciadas em seu marketing de turismo. Os autores identificaram que apesar de haver padronização nas imagens projetadas, também há diferenças significativas entre elas.

Na revisão da literatura também foram identificados estudos referentes ao marketing turístico no Brasil. Tomazzoni et al. (2010) analisaram o turismo na cidade de Bento Gonçalves. Os autores revelam que a cidade é um dos 65 destinos brasileiros que mais atraem turistas no país. Não obstante, baseando-se em indicadores de desenvolvimento, identificou-se ainda que o município necessita de melhoras em sua infraestrutura para atrair os turistas.

Santana (2008) destaca que o turismo no Brasil é um dos setores que mais cresceram a partir da década de 90.0 autor identificou que as ações de marketing da Secretaria de Turismo de Balneário Camboriú/SC não são relevantes na atração dos turistas. Evidencia-se ainda que os turistas brasileiros viajam para este destino pelo fato de familiares residirem no município, ou retornam pela experiência positiva que tiveram em outras oportunidades.

Desse modo, um dos pontos cruciais do marketing turístico é o marketing dos destinos, visto que os destinos detêm todos os interesses relacionados às atividades turísticas (Seaton \& Bennett, 1996). Com isso, o empenho para promover os destinos turísticos tem ocupado um lugar central diante da execução de projetos de marketing nesta área (Ekinci \& Hosany, 2006).

\section{Marca de Destinos}

A literatura aponta que o aumento da competitividade e similaridade entre os destinos turísticos proporcionaram maior relevância da marca para este setor (Kumar \& Nayak, 2014). Nesse sentido, evidencia-se uma relação positiva entre o marketing turístico e a marca de destinos, pois como os produtos e serviços, os destinos também podem desenvolver uma marca (Morgan \& Pritchard, 1998).

De acordo com Aaker (1991) a marca consiste em um nome e/ou símbolo distinto, usado para identificar os produtos ou serviços de determinada organização, distinguindo-os dos seus concorrentes. Seguindo essa mesma lógica, Blain, Levy e Ritche (2005) sugerem que a marca de destino corresponde a um grupo de atividades de marketing que consiste na criação de um nome, 
símbolo ou logotipo, permitindo assim, a identificação e diferenciação de um destino, e sendo capaz de estimular sua ligação emocional com o turista.

Hankinson (2001) postula que as investigações a cerca da marca de destinos tem se estendido por um vasto campo de interesse acadêmico, sendo evidenciado que a sua classificação e reconhecimento pelo consumidor são essenciais para a escolha e sucesso da mesma (Aaker, 1997). Desse modo, para que os profissionais de turismo apresentem características favoráveis dos seus destinos aos seus clientes e obtenham vantagem competitiva, tornou-se indispensável a criação de suas marcas (Kumar \& Nayak, 2014; Sharifsamet et al., 2020).

\section{Personalidade da Marca de Destinos}

Os estudos sobre a personalidade da marca datam do início dos anos 1960 (Ekinci \& Hosany, 2006), tendo adquirido importância a partir do estudo desenvolvido por Aaker (1997), nos Estados Unidos (Gómez-Aguilar et al., 2016). No entanto, a literatura científica aponta que o estudo da personalidade da marca de destinos turísticos ainda é recente (Kumar e Nayak, 2014; Hultmanet al., 2015; Sharifsamet et al., 2020).

Aaker (1997) desenvolveu uma escala com a intenção de medir as dimensões da personalidade da marca de produtos, conceituando-as como um grupo de aspectos humanos relacionados a uma marca (Gómez-Aguilar et al., 2016). A escala da personalidade da marca (BPS) foi constituída por 42 traços distribuídos em cinco dimensões gerais: Excitação, Sinceridade, Competência, Sofisticação e Robustez. A partir disso, a personalidade da marca foi empregada a diferentes culturas para examinar o consumo simbólico dos consumidores e seus efeitos sobre o comportamento (Aaker, Benet-Martinez, \& Arolera, 2001).

Nesse sentido, a primeira investigação utilizando-se da BPS foi realizada por Ekinci e Hosany (2006), com o intuito de mensurar a personalidade da marca de destinos. Ao perceberem que os turistas associavam traços de personalidade a lugares, os autores definiram a personalidade da marca de destinos como sendo o conjunto de atributos humanos associados a um destino. A partir de então, o campo de pesquisas acerca da personalidade da marca de destinos tem se expandido consideravelmente (Ekinci et al., 2007; Li \& Kaplanidou, 2013; Rojas-Méndez e. al., 2013).

O estudo de Ekinci e Hosany (2006) foi desenvolvido no Reino Unido e identificou a personalidade da marca do destino em três dimensões: Sinceridade, Excitação e Convivialidade. A partir desse momento, a personalidade da marca passou a ser considerada uma ferramenta adequada para a construção de marcas de destino, possibilitando a compreensão das percepções dos visitantes e apresentando os destinos como diferenciados (Gómez-Aguilar et al., 2016).

Em pesquisa semelhante, Murphy et al. (2007) buscaram conhecer as dimensões que formam a personalidade da marca de duas regiões da Austrália. Os resultados mostraram que a personalidade da marca da região de Cairns é formada pelas dimensões Sinceridade, Sofisticação, Atividades ao ar livre, de Classe superior e Honestidade; e na região de Whitsunday pelas dimensões de Excitação e Resistência.

Sahin e Baloglu (2011) investigaram os traços que constituem a personalidade da marca de Istambul, na percepção de turistas dos Estados Unidos, Europa e Ásia Oriental. Os achados mostraram que a personalidade da marca desse local é percebida de diferentes maneiras pelos visitantes de cada nacionalidade, 
apresentando relação com as dimensões Originalidade E Vibração, Convivência, Competência e Modernidade.

No que se refere ao contexto brasileiro, Moya e Jain (2013) analisaram como a personalidade da marca do México e Brasil é comunicada por meio do Facebook, identificando e comparando quais as características atribuídas a eles por usuários desta rede social. Os resultados mostraram que ambos os destinos comunicam personalidades da marca diferenciadas na página oficial do Facebook de cada país. Constatou-se ainda que a personalidade da marca do México foi percebida pelas dimensões Excitação e Sinceridade, já a do Brasil foi percebida pelas dimensões Sofisticação, Sinceridade e Entusiasmo.

Hultman et al. (2015) investigaram as interligações entre as características do destino turístico e a satisfação do cliente, a identificação com a marca, o boca a boca favorável e as intenções de revisitar o local. Evidenciou-se que os turistas atribuem traços distintos aos destinos turísticos e que a personalidade da marca influencia tanto na satisfação como na vontade de promover o local e revisitá-lo.

Seguindo a mesma linha de pesquisa, Gómez-Aguilar et al. (2016) realizaram uma investigação para mensurar os traços da personalidade da marca de destinos espanhóis das cidades Granada e Torremolinos. Os resultados revelaram que as cinco dimensões adotadas no estudo constituem a personalidade da marca desses destinos, sendo elas: Sinceridade; Excitação; Competência; Sofisticação e Robustez.

Desse modo, a escolha por um destino está fortemente relacionada á análise dos turistas quanto às características que o destino apresenta (Huybers, 2003). Portanto, perceber o comportamento dos turistas em relação à personalidade da marca do destino garante vantagens estratégicas às organizações de turismo, contribuindo para o alcance de seus objetivos (Ahmed; 1991; Qu et al., 2011; Hultman et al., 2015).

Nesse contexto foram identificadas na literatura diferentes escalas utilizadas para mensurar a personalidade da marca, inclusive a marca de destinos turísticos, em diferentes localidades (Aaker, 1997; Hosany et al., 2006; Ekinci et al., 2007; Kumar, 2016). Apresentam-se as escalas no Quadro 1, a seguir.

Quadro 1 - Escalas que medem a personalidade da marca de destinos

\begin{tabular}{|l|l|l|}
\hline Dimensão & \multicolumn{1}{|c|}{ Escala } & \multicolumn{1}{|c|}{ Autores } \\
\hline Sofisticação & $\begin{array}{l}\text { Glamouroso; direcionado ao público classe A; } \\
\text { boa aparência; charme. }\end{array}$ & Aaker (1997) \\
\hline Robustez & Difícil acesso; traços ocidentais; atrações ao ar livre. & Aaker (1997) \\
\hline Excitação & Emocionante; ousado; original. & Hosany et al. (2006) \\
\hline Convivialidade & Amigável; hospitaleiro; orientado para a família. & Ekinci et al. (2007) \\
\hline Ferocidade & Violento; depravado; vulgar. & Kumar( 2016) \\
\hline Conformidade & $\begin{array}{l}\text { Orientação religiosa do local; orientação política } \\
\text { do local; cultura do local. }\end{array}$ & Kumar( 2016) \\
\hline
\end{tabular}

Fonte - Elaborado pelos autores.

Com base na revisão literária e nos objetivos estabelecidos neste estudo, sugere-se como hipótese principal que em média os turistas brasileiros se consideram muito criteriosos ao escolherem por um destino turístico para passarem suas férias (H1). Considerando que os destinos que apresentam personalidades favoráveis possuem mais facilidade de influenciar o comportamento dos turistas 
(Chen \& Phou, 2013; Ekinci \& Hosany, 2006; Usakli \& Baloglu, 2011), foram elaboradas as sub-hipóteses H2, H3, H4 e H5.

H2: Há uma relação positiva entre critério de escolha dos turistas e a dimensão da personalidade da marca de destinos "Sofisticação"

H3: Há uma relação positiva entre critério de escolha dos turistas e a dimensão da personalidade da marca de destinos "Robustez";

H4: Há uma relação positiva entre critério de escolha dos turistas e a dimensão da personalidade da marca de destinos "Excitação";

H5: Há uma relação positiva entre critério de escolha dos turistas e a dimensão da personalidade da marca de destinos "Convivialidade".

\section{Fontes de Informações Sobre Destinos Turísticos}

Além da marca e personalidade da marca de destinos, a literatura afirma que as fontes de informações sobre destinos turísticos tem sido um dos assuntos mais investigados no setor de turismo (Llodrà-Riera et. al., 2015). As fontes de informações são consideradas um dos componentes que mais influenciam os turistas na escolha por um destino (Dey \& Sarma, 2010; Jacobsen \& Munar, 2012). Pois assim como no setor de produtos e serviços, o comportamento do turista também se inicia com a busca de informações, o que costuma permanecer até o final da viagem (Bieger \& Laesser, 2004; Coromina \& Camprubí, 2016).

De acordo com Xiang, Magnini e Fesenmaier (2015) a busca de informações feitas pelos turistas antes de realizarem uma viagem pode ser tida como um elemento essencial da experiência em relação à viagem, tendo em vista que os turistas normalmente necessitam de uma quantidade considerável de informações para planejar suas viagens. Desse modo, as fontes de informações podem impactar diversos pontos da tomada de decisão do turista, principalmente no que se refere à escolha do destino a ser visitado (Bieger \& Laesser, 2004).

Sheldon (2007, p. 399) afirma que a informação "é o sangue da indústria turística". Dessa maneira, compreender quais as fontes de informações mais interessantes para os turistas torna-se relevante para os profissionais de turismo (Bieger \& Laesser, 2004; Dey \& Sarma, 2010). Nesse contexto, foram identificados estudos que buscam perceber quais são as fontes de informações mais usadas pelos turistas e a sua influência na escolha por um destino. Citam-se os estudos de Sparks e Pan (2009), Dey e Sarma (2010), Sahin e Baloglu (2011) e Jacobsen e Munar (2012).

Nessa perspectiva, Sparks e Pan (2009) realizaram uma análise das fontes de informações usadas por turistas chineses, explorando como essas fontes os influenciam na escolha por um destino turístico.Os achados indicam que os programas de televisão e a internet são as fontes mais utilizadas por esses turistas ao buscarem por um destino.

Em estudo semelhante foi desenvolvido por Dey e Sarma (2010) com o intuito de analisar o uso de fontes de informações por turistas que visitavam uma região turística no nordeste da Índia. Os resultados apontam que as fontes de informações mais importantes para esses turistas são amigos/parentes e colegas. No entanto, alguns autores afirmam que a Internet também é considerada como uma 
das principais fontes de informações utilizadas pelos turistas ao decidirem por uma viagem (Jacobsen \& Munar, 2012).

Nesse sentido, na investigação de Sahin e Baloglu (2011) buscou-se identificar os traços que constituem a personalidade da marca de Istambul, na percepção de turistas oriundos dos EUA, Europa e Ásia Oriental. Os autores constataram que as principais fontes de informações usadas por turistas dos EUA são jornal, revistas e livros de viagens; amigos e parentes para os da Europa e internet para os da Ásia Oriental.

Na pesquisa desenvolvida por Jacobsen e Munar (2012) buscou-se analisar a importância de variadas fontes de informações utilizadas por turistas ao decidirem viajar para Mallorca, na Espanha. Evidenciou-se que entre as fontes de informações mais significativas para estes turistas estão amigos e familiares, e sites de hotéis.

0 uso de fontes de informações na busca por um destino turístico também foi investigado por Wang, Yu e Fesenmaier (2002), que buscaram definir um conceito de comunidades turísticas virtuais, evidenciando suas implicações para o marketing turístico. Identificou-se que para obter sucesso, as organizações de turismo devem fornecer aos seus clientes de comunidades turísticas virtuais uma forma semelhante de se expressar, de modo que possam atender as várias necessidades da comunidade com base nos aspectos fornecidos na Internet.

De modo geral, a literatura sugere que as fontes de informações são de grande relevância no processo de escolha por um destino, e que entre outras coisas, permite a formação de imagens cognitivas, afetivas e exclusivas do destino turístico, fornecendo fundamento base para analisar o comportamento dos turistas (LlodràRiera et al., 2015; Vinyals-Mirabent, Kavaratzis, \& Fernández-Cavia, 2019).

\section{METODOLOGIA}

Para identificar o critério de escolha dos turistas brasileiros ao decidir por um destino para passar suas férias optou-se por metodologia quantitativa, com caráter descritivo e corte transversal. 0 público alvo do estudo são turistas brasileiros. Por não ser possível alcançar esse universo, recorreu-se a uma amostragem não probabilística por acessibilidade. Adotou-se coleta primária de dados utilizando o formulário eletrônico Typeform. 0 questionário foi replicado por meio de correio eletrônico, WhatsApp, Messenger e pela rede social Facebook.

Em relação ao Facebook, utilizou-se também de anúncio pago com a intenção de aumentar o número de entrevistados. Esta medida teve como objetivo disponibilizar o questionário a turistas brasileiros de todas as regiões do país. Ressalta-se ainda que a coleta de dados estendeu-se durante os meses de outubro, novembro e dezembro de 2017.

Nesse contexto, desenvolveu-se um questionário composto por dezenove questões. 0 questionário baseia-se em escalas já validadas na literatura e subdivide-se nas seguintes dimensões: Convivialidade (Ekinci et al., 2007), Excitação (Hosany et al., 2006), Sofisticação, Robustez (Aaker, 1997), Ferocidade e Conformidade (Kumar, 2016).

Em seguida, foram inseridas também 6 (seis) questões para identificar quais fontes de informações o turista brasileiro leva em consideração para escolher um destino (Llodra-Riera et al., 2015). Como ferramenta de coleta das respostas utilizou-se a 
Escala de Likert composta por cinco posições, variando de (1) discordo totalmente a (5) concordo totalmente. Apresenta-se o questionário no Quadro 2 abaixo.

Quadro 2 - Questionário utilizado para coletar os dados

\begin{tabular}{|c|c|}
\hline Dimensões & Afirmações \\
\hline Variável Y & 1. Como turista me considero criterioso na escolha de um destino turístico; \\
\hline Convivialidade & $\begin{array}{l}\text { 2. Eu escolho o meu destino turístico pelo fato dele ser seguro; } \\
\text { 3. Eu escolho o meu destino turístico por ele ser hospitalar; } \\
\text { 4. Eu escolho o meu destino turístico por ele possuir uma orientação familiar; }\end{array}$ \\
\hline Excitação & $\begin{array}{l}\text { 5. Eu escolho o destino turístico pelo fato dele ser emocionante; } \\
\text { 6. Eu escolho meu destino turístico pelo fato dele ser ousado; } \\
\text { 7. Eu escolho meu destino turístico pelo fato dele ser original; }\end{array}$ \\
\hline Sofisticação & $\begin{array}{l}\text { 8. Eu escolho meu destino turístico pelo fato dele ser glamouroso; } \\
\text { 9. Eu escolho meu destino turístico pelo fato dele ser direcionado ao } \\
\text { público Classe A; } \\
\text { 10. Eu escolho meu destino turístico pela aparência da região; } \\
\text { 11. Eu escolho meu destino turístico pelo fato dele ser encantador; }\end{array}$ \\
\hline Robustez & $\begin{array}{l}\text { 12. Eu escolho meu destino turístico pelo fato dele ser um local de difícil acesso; } \\
\text { 13. Eu escolho destino turístico que possua traços ocidentais; } \\
\text { 14. Eu escolho destino turístico que tenha atrações ao ar livre; }\end{array}$ \\
\hline Ferocidade & $\begin{array}{l}\text { 15. Eu escolho meu destino turístico pelo fato dele ser violento; } \\
\text { 16. Eu escolho meu destino turístico pelo fato dele ser depravado; } \\
\text { 17. Eu escolho meu destino turístico pelo fato dele vulgar; }\end{array}$ \\
\hline Conformidade & $\begin{array}{l}\text { 18. Eu escolho meu destino turístico pela orientação religiosa do local; } \\
\text { 19. Eu escolho meu destino turístico pela orientação política do local; } \\
\text { 20. Eu escolho meu destino turístico pela cultura do local; }\end{array}$ \\
\hline $\begin{array}{l}\text { Fontes de } \\
\text { Informação }\end{array}$ & $\begin{array}{l}\text { 21. Intermediários (agências de viagens ou operadores turísticos) } \\
\text { 22. Mídia especializada em turismo; } \\
\text { 23. Guias de viagem; } \\
\text { 24. Documentários; } \\
\text { 25. Amigos e conhecidos; } \\
\text { 26. Internet }\end{array}$ \\
\hline
\end{tabular}

Fonte - Adaptado de Aaker (1997); Ekinci e Hosany (2006);

Ekinci et al. (2007); Kumar (2016); Llodra-Riera et al. (2015).

Para detalhar as características sociodemográficas dos turistas brasileiros foram inseridas perguntas visando identificar: gênero, idade, renda familiar, quantas viagens com fins turísticos realizam por ano. Por fim, utilizando-se a Escala de Likert composta por 05 posições, questionou-se o quanto o turista gosta de viajar. Obteve-se um total de 268 respostas de turistas brasileiros.

Nessa perspectiva, para analisar os dados, bem como responder o problema da presente pesquisa, realizou-se a caracterização da amostra para detalhar o perfil sociodemográfico do turista brasileiro; a análise das dimensões da personalidade da marca de destinos e das fontes de informações de um destino turístico sob a ótica da estatística descritiva, onde se analisa a média, desvio padrão, mínimo, quartil 1, mediana, quartil 3, e máximo; e regressão linear múltipla.

Utilizando-se modelo abaixo, a regressão linear múltipla tem como objetivo identificar o grau de associação das dimensões Convivialidade, Excitação, Sofisticação, Robustez,FerocidadeeConformidade(Ekincietal.,2007; Hosany etal., 2006; Aaker, 1997; Kumar, 2016) com a variável dependente (Y= Como turista 
me considero criterioso na escolha de um destino turístico). Utilizou-se também as informações sociodemográficas como variáveis de controle.

Modelo 1: Critério de seleção $=\beta 0+\sum_{i=1}^{6} \beta i X i+$ Controles $+E 1$

Em que:

$\mathrm{X} 1$ = Convivialidade;

X2 = Excitação;

$\mathrm{X} 3$ = Sofisticação;

$\mathrm{X} 4$ = Robustez;

$\mathrm{X} 5$ = Ferocidade;

X6 = Conformidade;

Controles: gênero, idade, renda, quantas viagens realiza por ano e o quanto gosta de viajar;

E1= Termo de erro.

\section{ANÁLISE DOS DADOS}

\section{Caracterização da Amostra}

Com o objetivo de identificar o critério de escolha dos turistas brasileiros ao decidir por um destino para passar suas férias obteve-se um total de 268 respostas válidas. Nesse contexto, apresentam-se na Tabela 1 as características sociodemográficas da amostra coletada em relação a gênero, idade, renda familiar, viagens com fins turísticos por ano e o quanto gosta de viajar.

Tabela 1 - Características dos Turistas Brasileiros

\begin{tabular}{|l|c|c|}
\hline Clientes & No & \% \\
\hline Gênero & & \\
\hline Masculino & 142 & 52,98 \\
\hline Feminino & 126 & 47,01 \\
\hline Total & $\mathbf{2 6 8}$ & $\mathbf{1 0 0}$ \\
\hline Idade & & 14,92 \\
\hline 18 a 25 anos & 40 & 48,50 \\
\hline 26 a 35 anos & 130 & 28,35 \\
\hline 36 a 45 anos & 76 & 5,22 \\
\hline 46 a 55 anos & 14 & 2,98 \\
\hline 56 anos ou mais & 8 & $\mathbf{1 0 0}$ \\
\hline Total & $\mathbf{2 6 8}$ & 14,55 \\
\hline Renda familiar & & 20,14 \\
\hline Até $R \$ 99,99$ reais & 39 & 19,02 \\
\hline Entre $R \$ 1000,00$ e $R \$ 2999,99$ & 54 & (continua...) \\
\hline Entre $R \$ 3000,00$ e $R \$ 4999,99$ & 51 & \\
\hline
\end{tabular}




\section{Tabela 1 - Continuação}

\begin{tabular}{|l|c|c|}
\hline Clientes & $\mathbf{N}$ & $\mathbf{\%}$ \\
\hline Entre $\mathrm{N} \$ 5000,00$ e $\mathrm{R} \$ 7999,99$ & 49 & 18,28 \\
\hline Mais que R $\$ 8000,00$ & 75 & 27,98 \\
\hline Total & $\mathbf{2 6 8}$ & $\mathbf{1 0 0}$ \\
\hline Viagens com fins turísticos por ano & & \\
\hline 01 viagem & 85 & 30,14 \\
\hline 02 viagens & 74 & 26,24 \\
\hline 03 viagens & 58 & 20,56 \\
\hline 04 viagens & 23 & 8,15 \\
\hline 05 ou mais viagens & 42 & 14,89 \\
\hline Total & $\mathbf{2 6 8}$ & $\mathbf{1 0 0}$ \\
\hline O quanto gosta de viajar & & 1,11 \\
\hline Não gosto & 3 & 4,10 \\
\hline Não gosto parcialmente & 11 & 9,32 \\
\hline Indiferente & 25 & 19,77 \\
\hline Gosto parcialmente & 53 & 65,67 \\
\hline Gosto muito & 176 & $\mathbf{1 0 0}$ \\
\hline Total & $\mathbf{2 6 8}$ & \\
\hline
\end{tabular}

Fonte - Dados da pesquisa.

De acordo com Tabela 1 percebe-se uma pequena diferença em relação ao gênero. Os homens representam 52,98\% da amostra, enquanto as mulheres representam 47,01\%. Majoritariamente a amostra é composta por pessoas com idade entre 26 a 35 anos (48,50\%), seguido por 36 a 45 anos (28,35\%). Em relação à renda familiar a amostra é formada por turistas brasileiros que recebem mais que $\mathrm{R} \$ 8.000,00$ (27,98\%), dividindo-se o restante de maneira parecida nas demais faixas salariais apresentadas.

Sobre a quantidade de viagens com fins turísticos por ano, a maioria da amostra declarou que realiza apenas 01 (uma) viagem por ano com essa finalidade $(30,14 \%)$, seguido de 02 (duas) viagens por ano $(26,24 \%)$. Por fim, em relação a quanto o turista brasileiro gosta de viajar, os dados revelam que os mesmos gostam muito de viajar (65,67\%), seguido de gostam parcialmente $(19,77 \%)$.

Portanto, percebe-se que em média o turista brasileiro possui um perfil jovem, com idade entre 26 a 35 anos, renda familiar superior a $\mathrm{R} \$ 8.000$, realizando em média de 1 a 2 viagens por ano com fins turísticos, e gostam muito de viajar. Destaca-se que as características da amostra obtida neste estudo são semelhantes às amostras de estudos anteriores realizados com turistas brasileiros (por exemplo, Mazzon \& Vera, 2008; Santos, Coutinho \& Teixeira, 2010; Carril, 2015; Bagega \& Werlang, 2018). Com base nisso, a amostra atingida é apropriada para responder aos objetivos desta investigação, possibilitando que sejam feitas comparações com pesquisas realizadas anteriormente (Da Silva, Mainardes, Teixeira, \& Costa Júnior, 2020). 


\section{Estatística Descritiva das Dimensões}

As dimensões de personalidade da marca de destinos turísticos (Aaker, 1997; Hosany et al., 2006; Ekinci et al., 2007; Kumar, 2016) são analisados na Tabela 2. Utilizou-se na estatística descritiva geral para analisar os dados a média, desvio padrão, mínimo, quartil 1, mediana, quartil 3, e máximo.

Tabela 2 - Estatística Descritiva Geral

\begin{tabular}{|c|c|c|c|c|c|c|c|}
\hline Variáveis & Média & DP & Min & Quartil1 & Mdn & Quartil3 & Máx. \\
\hline Criterioso na escolha (y) & 4,18 & 0,92 & 1,00 & 3,00 & 4,50 & 5,00 & 5,00 \\
\hline Convivialidade & 3,66 & 0,83 & 1,00 & 3,00 & 3,66 & 4,33 & 5,00 \\
\hline Excitação & 3,58 & 0,90 & 1,00 & 3,00 & 3,66 & 4,33 & 5,00 \\
\hline Sofisticação & 3,30 & 0,82 & 1,00 & 2,75 & 3,25 & 4,00 & 5,00 \\
\hline Robustez & 2,54 & 0,85 & 1,00 & 2,00 & 2,33 & 3,00 & 5,00 \\
\hline Ferocidade & 1,28 & 0,63 & 1,00 & 1,00 & 1,00 & 1,33 & 5,00 \\
\hline Conformidade & 2,36 & 0,84 & 1,00 & 1,66 & 2,33 & 3,00 & 5,00 \\
\hline Gênero & 0,52 & 0,50 & 0,00 & 0,00 & 1,00 & 1,00 & 1,00 \\
\hline Idade & 2,32 & 0,89 & 1,00 & 2,00 & 2,00 & 3,00 & 5,00 \\
\hline Renda Familiar & 3,25 & 1,42 & 1,00 & 2,00 & 3,00 & 5,00 & 5,00 \\
\hline Viagens com fins turísticos & 1,83 & 1,06 & 1,00 & 1,00 & 2,00 & 2,00 & 5,00 \\
\hline O quanto gosta de viajar & 4,44 & 0,90 & 1,00 & 4,00 & 5,00 & 5,00 & 5,00 \\
\hline Frequência em uma clínica & 4,15 & 0,98 & 1,00 & 4,00 & 5,00 & 5,00 & 5,00 \\
\hline
\end{tabular}

Fonte - Dados da pesquisa.

Observa-se que as dimensões com as maiores médias foram Convivialidade $(M=3,66)$, que está relacionada ao quanto o destino é hospitaleiro e voltado para a família (Ekinci et al., 2007) e Excitação $(\mathrm{M}=3,58)$ que está associada à originalidade, ousadia e ao quanto destino é emocionante (Hosany et al., 2006). Em relação à menor média encontrada revela-se a dimensão Ferocidade $(M=1,28)$, que é associada a um destino violento e vulgar (Kumar, 2016). 0 baixo desvio padrão neste construto $(M=0,63)$ revela que as respostas pouco se dispersaram na Escala de Likert.

Portanto, sugere-se que em média os turistas brasileiros preferem destinos em que se sintam bem acolhidos, com características e atividades que permitam diversão para toda a família. Não obstante, eles tendem a preferir um destino turístico original, que proporcione emoção e boas recordações do local e da viagem. Os resultados encontrados vão ao encontro dos achados de Ekinci et al. (2007), Murphy et al. (2007), Sahin e Baloglu (2011).

Em relação à variável $Y$, os dados revelam que o turista brasileiro em média $(M=4,18)$ considera-se bastante criterioso no planejamento, e consequentemente, na escolha do destino turístico. Nesse sentido confirma-se H1, que sugere que os turistas brasileiros se consideram muito criteriosos ao escolherem por um destino turístico para passarem suas férias. Com base nisso, sugere-se que ser criterioso nessa escolha seja consequência da satisfação final que o turista brasileiro busca em relação à viagem (Hultman et. al., 2015). 


\section{Análise Multivariada}

Com o objetivo de identificar o grau de associação das dimensões de personalidade da marca de destinos turísticos (Ekinci et al., 2007; Hosany et al., 2006; Aaker, 1997; Kumar, 2016) com a variável dependente (Y= Como turista me considero criterioso na escolha de um destino turístico), bem como confirmar ou rejeitar as sub-hipóteses, analisa-se os dados de acordo com a Tabela 3.

Ressalta-se que a regressão linear múltipla está dividida nos Painel $\mathrm{A}$ (sem controle) e Painel B (com controle). No Painel B foram inseridas as seguintes variáveis de controle: dummies relacionadas à idade, renda familiar, quantas viagens com fins turísticos realiza por ano e o quanto gosta de viajar.

Tabela 3 - Resultado da Regressão Levando-se em

Consideração Variáveis sem Controle e com Controle

Painel A: Sem controle

\begin{tabular}{|l|c|c|}
\hline \multicolumn{4}{|c|}{ Escolha de um destino turístico } \\
\hline Dimensões da personalidade da marca de destinos & Coeficiente & $\mathbf{P}>|\mathbf{t}|$ \\
\hline Convivialidade & 0,22 & $0,00^{* * *}$ \\
\hline Excitação & 0,14 & $0,03^{* *}$ \\
\hline Sofisticação & 0,39 & $0,00^{* * *}$ \\
\hline Robustez & $-0,17$ & $0,02^{* *}$ \\
\hline Ferocidade & 0,03 & 0,69 \\
\hline Conformidade & 0,05 & 0,51 \\
\hline Número de observações: & & $\mathbf{2 6 8}$ \\
\hline
\end{tabular}

Painel B: Com controle

\begin{tabular}{|l|c|c|}
\hline \multicolumn{4}{|c|}{ Escolha de um destino turístico } \\
\hline Dimensões da personalidade da marca de destinos & Coeficiente & $\mathbf{P}>|\mathbf{t}|$ \\
\hline Convivialidade & 0,21 & $0,00^{* * *}$ \\
\hline Excitação & 0,13 & 0,06 \\
\hline Sofisticação & 0,33 & $0,00^{* * *}$ \\
\hline Robustez & $-0,12$ & 0,12 \\
\hline Ferocidade & 0,08 & 0,33 \\
\hline Conformidade & 0,06 & 0,43 \\
\hline Idade & 0,07 & 0,19 \\
\hline Renda & 0,12 & $0,00 * * *$ \\
\hline Quantas viagens com fins turísticos por ano & $-0,08$ & 0,10 \\
\hline O quanto gosta de viajar & 0,16 & $0,00^{* * *}$ \\
\hline Número de observações: & & $\mathbf{2 6 8}$ \\
\hline
\end{tabular}

\footnotetext{
Fonte - Elaboração própria. ${ }^{* *} \mathrm{e}^{* * *}$ representam
}

coeficientes significativos a $5 \%$ e $1 \%$, respectivamente.

No Painel A observa-se que as dimensões "Convivialidade" $(0,22)$ e "Sofisticação" $(0,39)$ estão associadas positivamente ao critério de escolha dos 
turistas brasileiros, com um intervalo de confiança de $99 \%$. Nesse contexto são confirmadas as hipóteses H2 e H5. Destaca-se, portanto, que características do destino como amigável, charmoso e encantador, são variáveis que o turista leva em consideração no momento de escolher o local para passar as suas férias (Aaker, Benet-Martinez, \& Arolera, 2001; Moya \& Jain, 2013).

Com $95 \%$ de confiança o construto "Excitação" $(0,14)$ está associado positivamente ao critério de escolha dos turistas brasileiros. Nesse sentido confirma-se a hipótese H4. Dessa maneira sugere-se que locais que proporcionem emoção e sejam originais tendem a ser levados em consideração pelo turista brasileiro ao decidir pelo destino turístico para passar as férias (Ekinci \& Hosany, 2006; Murphy et al., 2007).

A dimensão "Robustez" $(-0,17)$ também foi associada ao critério de escolha do turista brasileiro com 95\% de confiança, porém de maneira negativa (Gómez-Aguilar et al., 2016). Nesse sentido, locais de difícil acesso e com atrações ao ar livre não são considerados relevantes na escolha desse turista por um destino. Nesse contexto rejeita-se a hipótese H3. 0 resultado pode proporcionar uma discussão na literatura comparando-se com o estudo de Bagega e Werlang (2018), que buscam identificar fatores relevantes para incentivar o turismo rural.

No Painel B, após inserir-se as Dummies, percebe-se que apenas as dimensões “Convivialidade" $(0,21)$ e "Sofisticação" $(0,33)$ permanecem associadas à variável dependente (Murphy et al., 2007), ambas de maneira positiva e com intervalo de confiança de $99 \%$. Não obstante, observa-se que as variáveis de controle "Renda" $(0,12)$ e "O quanto gosta de viajar" $(0,16)$ também estão associadas positivamente ao critério de escolha do turista brasileiro, com intervalo de confiança de 99\%.

Levando em consideração que na caracterização da amostra os respondentes afirmaram gostar muito de viajar, e que em média ganham mais que $\mathrm{R} \$ 8.000,00$ mensais, compreendem-se os motivos pelos quais um local direcionado ao público classe A e de boa aparência seja relevante para este perfil de turista.

\section{Estatística Descritiva das Fontes de Informações}

Com o objetivo de identificar o grau de relevância das fontes de informações utilizadas pelos turistas brasileiros na busca por um destino turístico, apresenta-se na Tabela 4 analises estatísticas em relação a: Agência de viagens, Mídia especializada em turismo, Guias de viagem, Documentários, Amigos e conhecidos, e Internet (Llodrà-Riera et al., 2015).

Tabela 4 - Estatística Descritiva - Fontes de Informação ao Escolher um Destino Turístico

\begin{tabular}{|l|c|c|c|c|c|c|c|}
\hline Variáveis & Média & DP & Min & Quartil1 & Mdn & Quartil3 & Máx. \\
\hline Agências de viagens & 3,54 & 1,20 & 1,00 & 3,00 & 3,00 & 5,00 & 5,00 \\
\hline $\begin{array}{l}\text { Mídia especializada } \\
\text { em turismo }\end{array}$ & 3,73 & 1,09 & 1,00 & 3,00 & 4,00 & 5,00 & 5,00 \\
\hline Guias de viagem & 3,63 & 1,17 & 1,00 & 3,00 & 4,00 & 5,00 & 5,00 \\
\hline Documentários & 3,41 & 1,28 & 1,00 & 2,00 & 3,00 & 5,00 & 5,00 \\
\hline Amigos e conhecidos & 4,36 & 0,84 & 1,00 & 4,00 & 5,00 & 5,00 & 5,00 \\
\hline
\end{tabular}




\begin{tabular}{|c|c|c|c|c|c|c|c|}
\hline Internet & 4,36 & 0,86 & 1,00 & 4,00 & 5,00 & 5,00 & 5,00 \\
\hline
\end{tabular}

Os dados revelam uma paridade em relação às fontes que apresentaram as maiores médias. Evidencia-se que as fontes "Amigos e Conhecidos" $(M=4,36)$ e "Internet" $(M=4,36)$ em média são as mais relevantes para os turistas brasileiros na busca por um destino turístico. Os resultados vão ao encontro das pesquisas de Wang, Yu e Fesenmaier (2002), Mazzon e Vera (2008), Sparks e Pan (2009), Dey e Sarma (2010), Jacobsen e Munar (2012).

Utilizando-se o desvio padrão como critério de desempate, buscou-se identificar onde houve uma menor dispersão das respostas, portanto, "Amigos e Conhecidos" apresentou um DP= $(0,84)$, ficando em primeiro lugar (Sahin \& Baloglu, 2011). Nesse contexto, em média o turista brasileiro buscar ouvir experiências que amigos e conhecidos obtiveram em suas viagens, bem como utilizam a internet para buscar informações que permitam planejar melhor sua viagem.

Com base nos resultados apresentados, torna-se relevante que as organizações envolvidas com o turismo utilizem a Internet como fonte de informação sobre os seus destinos. Além disso, torna-se relevante também que desenvolvam estratégias capazes de gerar em seus clientes o boca a boca positivo, pois "Amigos e Conhecidos" foram apontados como sendo a principal fonte de informações que os turistas brasileiros consideram ao decidirem por um destino turístico.

\section{CONSIDERAÇÕES FINAIS}

A presente pesquisa teve como objetivo identificar o critério de escolha dos turistas brasileiros ao decidirem por um destino para passarem suas férias. Buscou-se também perceber a relação entre o critério de escolha dos turistas e a personalidade da marca de destinos; verificar os traços que constituem a personalidade da marca de destinos na visão dos turistas brasileiros; e perceber o grau de relevância das diferentes fontes de informações utilizadas pelos turistas brasileiros na busca por um destino turístico.

Identificou-se que o turista brasileiro tem em média um perfil jovem, gosta muito de viajar, realiza duas viagens com fins turísticos por ano e faz parte de famílias com média e alta renda. Identificou-se ainda que em média o turista brasileiro considera-se bastante criterioso na escolha de um destino turístico para passar suas férias. Os dados sugerem ainda que o brasileiro analisa previamente diversas possibilidades, para posteriormente definir o destino. Nesse sentido, buscar conhecer as experiências de amigos e conhecidos, bem como ler relatos de outros turistas em conceituados sites da internet como o TripAdvisor são importantes para a decisão do turista brasileiro.

Sugere-se ainda que o turista brasileiro procure por lugares onde se sinta bem recepcionado e que possua atividades destinadas tanto para adultos, como para as crianças. Para este turista o destino turístico deve ser ousado e emocionante, proporcionando boas recordações para os envolvidos na viagem. Ainda em relação às médias encontradas, apesar de cidades como o Rio de Janeiro investir em tours pelas favelas cariocas, o turista brasileiro procura com menos intensidade 
locais que são associados à violência. Nesse contexto, o primeiro problema de pesquisa foi respondido.

No tocante a regressão linear, os resultados evidenciam que as maiores médias encontradas na estatística descritiva de fato estão associadas à escolha do turista brasileiro. Adiciona-se ainda que em média a amostra é composta por respondentes que pertencem a famílias ricas e que gostam muito de viajar. Portanto, é relevante para estes turistas que o destino seja de boa aparência e que tenha como público alvo famílias de alta renda. Dessa maneira o segundo problema da pesquisa também foi respondido, e consequentemente o objetivo principal do estudo foi atingido.

A presente pesquisa contribui com a literatura científica avançando com temas relacionados ao marketing turístico, marca e personalidade da marca de destinos turísticos. Preenche-se a lacuna apresentada e identifica-se a relação existente entre a personalidade da marca de destinos turísticos que são considerados relevantes pelos turistas brasileiros e o critério de escolha dos mesmos. Como contribuição prática, os resultados obtidos neste estudo podem proporcionar as organizações envolvidas com turismo uma visão holística acerca dos traços da personalidade da marca de destinos turísticos que são considerados pelos turistas brasileiros. Tais informações permitirão aos gestores adotarem estratégias que vão ao encontro dos anseios do turista brasileiro. 0 que pode vir a contribuir para que obtenham vantagens competitivas diante dos concorrentes.

Admite-se como limitação o fato do Brasil ser um país com dimensões continentais, com culturas, costumes e crenças distintas em todas as regiões, aspectos esses que não foram abordados no presente estudo, mas que são recomendados para investigações futuras. Portanto, torna-se difícil generalizar a opinião do turista brasileiro quanto ao que consideram em suas decisões por um destino e suas personalidades de destinos preferíveis. 0 que faz com que os resultados apresentados neste estudo não possam ser estendidos a todos os turistas brasileiros. Outra limitação é o fato da pesquisa investigar apenas um tipo de destino turístico, que é o turismo de férias, não abordando outros tipos de turismo, como por exemplo, o turismo de negócios, que aumenta consideravelmente a população flutuante de cidades como São Paulo/SP e Brasília/DF. Desse modo, recomenda-se a realização de estudos que investiguem a personalidade da marca desse tipo de destino turístico.

Desta forma, para futuras pesquisas sugere-se a realização de estudos com a mesma temática, porém, ampliando o número da amostra e criando dummies relacionadas à qual região do país o respondente pertence. Recomenda-se ainda atribuir à personalidade da marca a uma cidade em especifico, por exemplo, Rio de Janeiro/RJ, Orlando (Estados Unidos), Paris (França) e Dubai (Emirados Árabes). Por fim, recomenda-se também identificar o critério de escolha dos turistas que viajam a trabalho (turismo de negócios) e dos que viajam por motivos de estudo, por exemplo, para apresentar trabalhos em congressos ou realizar algum curso presencial (turismo pedagógico ou turismo educacional).

\section{REFERÊNCIAS}

Aaker, D. A., \& Equity, M. B. (1991). The Free Press. New York, 206. 
Aaker, J. L. (1997). Dimensions of brand personality. Journal of Marketing Research, 34(3), 347-356.

Aaker, J. L., Benet-Martinez, V., \& Garolera, J. (2001). Consumption symbols as carriers of culture: A study of Japanese and Spanish brand personality constucts. Journal of Personality and Social Psychology, 81(3), 492.

Ahmed, Z. U. (1991). The influence of the components of a state's tourist image on product positioning strategy. Tourism Management, 12(4), 331-340.

Bagega, C. S., \& Berger Werlang, N. (2018). Fatores relevantes para a implantação de um roteiro turístico rural: um estudo a partir da percepção dos turistas. Capital Científico, 16(2).

Beerli, A., \&Martín, J. D. (2004). Tourists' characteristics and the perceived image of tourist destinations: a quantitative analysis-a case study of Lanzarote, Spain. Tourism Management, 25(5), 623-636.

Bieger, T., \& Laesser, C. (2004). Information sources for travel decisions: Toward a source process model. Journal of Travel Research, 42(4), 357-371.

Blain, C., Levy, S. E., \& Ritchie, J. B. (2005). Destination branding: Insights and practices from destination management organizations. Journal of Travel Research, 43(4), 328-338.

Bramwell, B., \& Rawding, L. (1996). Tourism marketing images of industrial cities. Annals of Tourism Research, 23(1), 201-221.

Buhalis, D., \& Law, R. (2008). Progress in information technology and tourism management: 20 years on and 10 years after the Internet -The state of e Tourism research. Tourism Management, 29(4), 609-623.

Carril, B. P. R. (2015). Motivações das publicações de fotos de viagens: Facebook e Instagram como instrumentos influenciadores no turismo. Trabalho de Conclusão de Curso. Universidade Federal Fluminense.

Chen, C. F., \&Phou, S. (2013). A closer look at destination: Image, personality, relationship and loyalty. Tourism Management, 36, 269-278.

Coromina, L., \&Camprubí, R. (2016). Analysis of tourism information sources using a Mokken Scale perspective. Tourism Management, 56, 75-84.

Da Silva, L. C., Mainardes, E. W., Teixeira, A. M. C., \& Costa Júnior, L. (2020). Brand orientation of nonprofit organizations and its relationship with the attitude toward charity and donation intention. International Review on Public and Nonprofit Marketing, 17, p. 1-21. DOI: https://doi.org/10.1007/s12208-020-00251-6.

Dey, B., \& Sarma, M. K. (2010). Information source usage among motive-based segments of travelers to newly emerging tourist destinations. Tourism Management, 31(3), 341-344.

Ekinci, Y., \& Hosany, S. (2006). Destination personality: An application of brand personality to tourism destinations. Journal of Travel Research, 45(2), 127-139.

Ekinci, Y., Sirakaya-Turk, E., \& Baloglu, S. (2007). Host image and destination personality. Tourism Analysis, 12(5-6), 433-446.

Gómez-Aguilar, A., Yagüe Guillén, M. J., \& Villaseñor Roman, N. (2016). Destination brand personality: An application to Spanish tourism. International Journal of Tourism Research, 18(3), 210-219.

Guido, G., \&Peluso, A. M. (2015). Brand anthropomorphism: Conceptualization, measurement, and impact on brand personality and loyalty. Journal of Brand Management, 22(1), 1-19.

Hankinson, G. (2001). Location branding: A study of the branding practices of 12 English cities. Journal of Brand Management, 9(2), 127-142. 
Hankinson, G. (2005). Destination brand images: a business tourism perspective. Journal of Services Marketing, 19(1), 24-32.

Hosany, S., Ekinci, Y., \& Uysal, M. (2006). Destination image and destination personality: An application of branding theories to tourism places. Journal of business research, 59(5), 638-642.

Hosany, S., Ekinci, Y., \&Uysal, M. (2007). Destination image and destination personality. International Journal of Culture, Tourism and Hospitality Research, 1(1), 62-81.

Hultman, M., Skarmeas, D., Oghazi, P., \& Beheshti, H. M. (2015). Achieving tourist loyalty through destination personality, satisfaction, and identification. Journal of Business Research, 68(11), 2227-2231.

Huybers, T. (2003). Domestic tourism destination choices - a choice modelling analysis. International Journal of Tourism Research, 5(6), 445-459.

Jacobsen, J. K. S., \& Munar, A. M. (2012). Tourist information search and destination choice in a digital age. Tourism Management Perspectives, 1, 39-47.

Kumar, V. (2016). Examining the role of destination personality and self-congruity in predicting tourist behavior. Tourism Management Perspectives, 20, 217-227.

Kumar, V., \& Nayak, J. K. (2014). The measurement \& conceptualization of destination personality. Tourism Management Perspectives, 12, 88-93.

Li, X., \& Kaplanidou, K. (2013). The impact of the 2008 Beijing Olympic Games on China's destination brand: A US-based examination. Journal of Hospitality \& Tourism Research, 37(2), 237-261.

Llodrà-Riera, I., Martínez-Ruiz, M. P., Jiménez-Zarco, A. I., \& Izquierdo-Yusta, A. (2015). A multidimensional analysis of the information sources construct and its relevance for destination image formation. Tourism Management, 48, 319-328.

Mazzon, J. A., \& Vera, L. A. N. (2008). A opinião dos turistas de negócios sobre a Imagem da Cidade de São Paulo. Revista Turismo em Análise, 19(3), 345-368.

Morgan, N., \& Pritchard, A. (1998). Tourism promotion and power: Creating images, creating identities. John Wiley \& Sons Ltd.

Moya, M., \& Jain, R. (2013). When tourists are your "friends": Exploring the brand personality of Mexico and Brazil on Facebook. Public Relations Review, 39(1), 23-29.

Murphy, L., Benckendorff, P., \& Moscardo, G. (2007). Linking travel motivation, tourist self-image and destination brand personality. Journal of Travel \& Tourism Marketing, 22(2), 45-59.

Papadimitriou, D., Apostolopoulou, A., \& Kaplanidou, K. (2015). Destination personality, affective image, and behavioral intentions in domestic urban tourism. Journal of Travel Research, 54(3), 302-315.

Pimentel, E., Pinho, T., \& Vieira, A. (2006). Iimagem da Marca de un Destino Turístico. TurismoVisão e Ação, 8(2), 283-298.

Qu, H., Kim, L. H., \&Im, H. H. (2011). A model of destination branding: Integrating the concepts of the branding and destination image. Tourism management, 32(3), 465-476.

Rojas-Méndez, J. I., Murphy, S. A., \& Papadopoulos, N. (2013). The US brand personality: A Sino perspective. Journal of Business Research, 66(8), 1028-1034.

Sahin, S., \& Baloglu, S. (2011). Brand personality and destination image of Istanbul. AnatoliaAn International Journal of Tourism and Hospitality Research, 22(01), 69-88.

Santana, G. G. (2008). Avaliação da adequação e eficácia de programas de marketing de destinos turísticos: uma análise de Balneário Camboriú-Santa Catarina, Brasil. Revista Turismo em Análise, 19(3), 424-449. 
Santos, C. A. M. D., Coutinho, H. R. M., \& Teixeira, M. A. S. B. (2010). As Impressões do Turista Brasileiro a Respeito da Gastronomia Amazonense. VII Seminário da Associação Nacional Pesquisa e Pós-Graduação em Turismo. - Universidade Anhembi Morumbi UAM/ São Paulo/SP.

Seaton, A. V., \& Bennett, M. M. (1996). The marketing of tourism products: Concepts, issues and cases. Cengage Learning EMEA.

Sharifsamet, S., Jin, H. S., \& Martin, B. (2020). Marketing destinations: the impact of destination personality on consumer attitude. Journal of Strategic Marketing, 28(1), 60-69.

Sheldon, P. J. (2007). 18 Tourism information technology. International Handbook on the Economics of Tourism, 399.

Shin, S. H., Yang, S. B., Nam, K., \& Koo, C. (2017). Conceptual foundations of a landmark personality scale based on a destination personality scale: Text mining of online reviews. Information Systems Frontiers, 19(4), 743-752.

Sousa, B., \& Simões, C. (2010). Comportamento e perfil do consumidor de turismo de nichos. Tékhne-Revista de EstudosPolitécnicos, (14), 137-146.

Sparks, B., \& Pan, G. W. (2009). Chinese outbound tourists: Understanding their attitudes, constraints and use of information sources. Tourism Management, 30(4), 483-494.

Tomazzoni, E. L., Possamai, A. M., \& Lovatel, R. (2010). Turismo no município de Bento Gonçalves (RS): análise do desenvolvimento de um destino indutor no Brasil. Revista Brasileira de Pesquisa em Turismo, 4(2).

Usakli, A., \&Baloglu, S. (2011). Brand personality of tourist destinations: An application of self-congruity theory. Tourism management, 32(1), 114-127.

Vinyals-Mirabent, S., Kavaratzis, M., \& Fernández-Cavia, J. (2019). The role of functional associations in building destination brand personality: When official websites do the talking. Tourism Management, 75, 148-155.

Wang, Y., Yu, Q., \& Fesenmaier, D. R. (2002). Defining the virtual tourist community: implications for tourism marketing. Tourism Management, 23(4), 407-417.

Xiang, Z., Magnini, V. P., \& Fesenmaier, D. R. (2015). Information technology and consumer behavior in travel and tourism: Insights from travel planning using the internet. Journal of Retailing and Consumer Services, 22, 244-249.

Recebido em: 25/09/2019

Aprovado em: 12/12/2019

\section{CONTRIBUIÇÃo}

Leonilde da Conceição Silva: Definição do problema de pesquisa e objetivos; desenvolvimento da proposição teórica; realização da revisão bibliográfica e fundamentação teórica; escolha dos procedimentos metodológicos; revisão crítica do manuscrito; redação do manuscrito e adequação do manuscrito às normas da RTA.

Lindemberg Costa Júnior: Coleta de dados; análise de dados; elaboração de tabelas, gráficos e figuras; realização de cálculos e projeções; revisão crítica do manuscrito; redação do manuscrito e adequação do manuscrito às normas da RTA. 